\title{
Subcellular mapping of living cells via synchrotron microFTIR and $\mathrm{ZnS}$ hemispheres
}

\author{
K. L. Andrew Chan ${ }^{1} \cdot$ Pedro L. V. Fale ${ }^{1,2} \cdot$ Ali Atharawi $^{1} \cdot$ Katia Wehbe $^{3} \cdot$ Gianfelice Cinque $^{3}$
}

Received: 16 May 2018 / Revised: 25 June 2018 / Accepted: 4 July 2018 / Published online: 21 July 2018

(C) The Author(s) 2018

\begin{abstract}
FTIR imaging is a label-free, non-destructive method valuably exploited in the study of the biological process in living cells. However, the long wavelength/low spatial resolution and the strong absorbance of water are still key constrains in the application of IR microscopy ex vivo. In this work, a new retrofit approach based on the use of $\mathrm{ZnS}$ hemispheres is introduced to significantly improve the spatial resolution on live cell FTIR imaging. By means of two high refractive index domes sandwiching the sample, a lateral resolution close to $2.2 \mu \mathrm{m}$ at $6 \mu \mathrm{m}$ wavelength has been achieved, i.e. below the theoretical diffraction limit in air and more than twice the improvement (to $\sim \lambda / 2.7$ ) from our previous attempt using $\mathrm{CaF}_{2}$ lenses. The $\mathrm{ZnS}$ domes also allowed an extended spectral range to $950 \mathrm{~cm}^{-1}$, in contrast to the cut-off at $1050 \mathrm{~cm}^{-1}$ using $\mathrm{CaF}_{2}$. In combination with synchrotron radiation source, microFTIR provides an improved signal-to-noise ratio through the circa $12 \mu \mathrm{m}$ thin layer of medium, thus allowing detailed distribution of lipids, protein and nucleic acid in the surround of the nucleus of single living cells. Endoplasmic reticula were clearly shown based on the lipid $v(\mathrm{CH})$ and $v(\mathrm{C}=\mathrm{O})$ bands, while the DNA was imaged based on the $v\left(\mathrm{PO}_{2}{ }^{-}\right)$band highlighting the nucleus region. This work has also included a demonstration of drug (doxorubicin) in cell measurement to highlight the potential of this approach.
\end{abstract}

Keywords FT-IR imaging $\cdot$ Fourier transform infrared $\cdot$ High definition $\cdot$ Cell systems/single cell analysis $\cdot$ Immersion objective $\cdot$ Anti-cancer drugs

\section{Introduction}

MicroFTIR is a chemically specific, non-destructive analytical method which does not require any external labelling for molecule tracking. IR spectroscopy advantageously uses low energy photons thereby avoiding unwanted fluorescence, photo-bleaching or light-induced sample damage. Measured

Electronic supplementary material The online version of this article (https://doi.org/10.1007/s00216-018-1245-x) contains supplementary material, which is available to authorized users.

K. L. Andrew Chan

Ka_lung.chan@kcl.ac.uk

1 Institute of Pharmaceutical Science, School of Cancer and Pharmaceutical Science, King's College London, London SE1 9NH, UK

2 Center of Chemistry and Biochemistry, Faculty of Sciences, University of Lisbon, 1749-016 Lisbon, Portugal

3 Diamond Light Source, Harwell Science and Innovation Campus, Didcot OX11 0DE, UK
IR absorbance follows the Beer-Lambert's law and therefore FTIR can be used as a quantitative technique. Significantly, it can be used to analyse living cells in situ without interfering on natural biological process. Monitoring living cells in their culture medium by FTIR imaging has been recognised as a powerful method for living cell studies [1-10]. Information obtained from living cells is more physiologically significant than from fixed cells. Light scattering from live cell measurement is inherently far less severe compared to dried cell measurements because of the smaller difference in refractive index between the cell and the surrounding medium [11].

When measuring live cells by FTIR, three major challenges to be considered are the strong IR absorbance of water in the cell culture medium and within the cell itself, the biocompatibility of the IR substrate and the limited spatial resolution relative to visible microscopy and in terms of subcellular structures. To experimentally overcome the strong absorbance of water, a number of approaches have been derived including using the attenuated total reflection (ATR) method, which probes the attached living cell without significant contribution from the water in the culture medium $[3,4,6,7]$, the use of a small path length liquid cells or microfluidic transmission cell 
with spacer matching to the thickness of the cell [12-15]. Synchrotron-based FTIR microscopy is also often used to achieve diffraction limited resolution and to enhance the signal to noise ratio [5, 12, 16-21]. In ATR mode, the live cell layer attached to the ATR element absorbs the evanescent wave generated during the internal reflection, which probes up to a few micrometres into the cell depending on the refractive index, $n$, of the element and the sample, and the angle of incidence [22]. Germanium was found to be a suitable substrate for cell attachment, and its high refractive index significantly increases the numerical aperture of the optical system (up to fourfold) which allows the imaging of subcellular features $[3,22]$. However, the high refractive index of Ge also results in a relatively small depth of penetration and path length therefore the spectra may neither be presentative of the cell bulk content nor have high absorbance signal. Furthermore, we recently found that bare Ge element can be damaged by the attached living cells and a coating is needed to reduce the damage [23]. When higher SNR and a full bulk measurement of cells is desirable, transmission mode measurement should be used. In this mode, living cells are seeded on an infrared transparent window and confined into a liquid cell by two windows. Infrared spectra of individual single living cells can be measured using an infrared microscope by either mapping with an aperture size matching or smaller than the size of the cell or with an imaging focal plane array detector [20, 21, 24]. However, microscopic imaging measurement through a standard IR liquid transmission cell with standard IR windows (usually 4-6 mm thick) has shown to be heavily affected by chromatic aberration due to refraction of IR light at the air-window interface $[25,26]$. By placing a $\mathrm{CaF}_{2}$ lens on the transmission cell window with a correct centre thickness to create a "hemispherical lens" on the sample, the chromatic aberration can be eliminated with the added advantage of increasing the magnification and spatial resolution of the resultant image [27]. It has been shown that this approach allows imaging of single cells in wax printed microfluidic channels in a standard transmission IR cell [12]. The improvement on spatial resolution via the "hemisphere" was found to be determined by the refractive index of the lens, i.e. $\sim 1.4$ times when $\mathrm{CaF}_{2}$ was used. It is expected that a higher magnification and spatial resolution can be obtained when a hemisphere with higher refractive index is used. $\mathrm{ZnSe}$ is a popular IR transparent substrate that has a refractive index of 2.4 but was found to be not compatible to a large number of cell lines [28]. ZnS, in contrary to a recent article [29], was found to be highly compatible to a large number of cell lines $[6,7,28]$ and has a high refractive index of 2.25 . Using ZnS hemispheres in FTIR microscopy, therefore, should increase the spatial resolution by 2.25 -fold, allowing to achieve subcellular FTIR image of live cells in transmission mode, which is not demonstrated before. While the method improves the overall quality of the image and spectrum, the
SNR could be limited due to the strong absorbance of water in the mid-IR region and the small aperture required for high spatial resolution measurement. The higher refractive index of $\mathrm{ZnS}$ (compares to $\mathrm{CaF}_{2}$ and when used without antireflection coating) also increases reflection loss potentially resulting in a lower throughput of light. The main aim of this study is to demonstrate the combined $\mathrm{ZnS}$ hemispherical lens approach with the synchrotron radiation that can maximise the signal and achieve both spectral quality and spatial resolving power for live subcellular studies. As a first step, we measured the 1951 United State Airforce (USAF) resolution target to demonstrate the achieved lateral spatial resolution with two different aperture and step size. Then, we image the distribution of different chemical components in full thickness living cells to identify the subcellular organelles in the surrounding of the nucleus using synchrotron FTIR microspectroscopy as an example of the potential applications. This will pave the way to study in situ drug interactions with live cells for the monitoring of both drug and biochemical changes in cells during drug treatment at subcellular level.

\section{Method}

\section{Synchrotron FTIR microscopy}

The experiment was carried out at the B22 beamline (MIRIAM) of the Diamond Light Source synchrotron facility. The system is comprised of a Vertex 80v FTIR spectrometer and a Hyperion 3000 microscope system (Bruker optics) with a $36 \times$ reverse Cassegrain reflective objective (NA $=0.5$ in air) and a matching condenser. A high sensitivity mid-band mercury cadmium telluride (MCT) single element detector was used for the mapping experiment. This is $50 \mu \mathrm{m}$ pitch size and has a cut-off at circa $650 \mathrm{~cm}^{-1}$. A multilayer Ge filter was used to reduce the spectral range below $4000 \mathrm{~cm}^{-1}$ of the incoming beam, and the detector non-linearity was software corrected during acquisition.

\section{Resolution target measurement}

An 8-mm diameter $\mathrm{ZnS}$ hemisphere was placed directly on the 1951 USAF resolution target (Newport Corporation) with the centre of the hemisphere aligned to the group 7 element 6 feature which contains 228.1 line pair per $\mathrm{mm}$, i.e. line width of $2.19 \mu \mathrm{m}$. The signal was optimised in reflection mode on a reflective area $\sim 15 \mu \mathrm{m}$ away from the line feature where a background measurement was also measured. Water was added to fill the gap between the hemisphere and the resolution target to improve the visibility of the feature. Images were obtained by scanning using a $6 \mu \mathrm{m} \times 6 \mu \mathrm{m}$ aperture size in air (i.e. $2.7 \mu \mathrm{m} \times 2.7 \mu \mathrm{m}$ through the $\mathrm{ZnS}$ hemisphere) with a step size of $2 \mu \mathrm{m}$ (i.e. $0.89 \mu \mathrm{m}$ through the $\mathrm{ZnS}$ hemisphere) 
and a set aperture size of $3 \mu \mathrm{m} \times 3 \mu \mathrm{m}$ in air (i.e. $1.3 \mu \mathrm{m} \times$ $1.3 \mu \mathrm{m}$ through the $\mathrm{ZnS}$ hemisphere) with a set step size of $1 \mu \mathrm{m}$ (i.e. $0.44 \mu \mathrm{m}$ through the $\mathrm{ZnS}$ hemisphere). Measurements were obtained by averaging 16 scans at $4 \mathrm{~cm}^{-1}$ spectral resolution giving a scanning time of 2-3 s per spectrum.

\section{Live cell measurement}

A549 cells (86012804 Sigma) were used in this experiment. Cells were grown in the Diamond B22 cell culture lab nearby the beamline. They were DMEM supplemented with $10 \%$ foetal bovine serum (FBS), $2 \mathrm{mM}$ L-glutamine and 100 unit/ $\mathrm{mL}$ penicillin streptomycin in a T25 tissue culture flask and incubated in a $5 \% \mathrm{CO}_{2}$ incubator. Cells are harvested when reached $\sim 80 \%$ confluency. The harvested cells were suspended in fresh DMEM medium at 100,000 cells per mL and $100 \mu \mathrm{L}$ of the cell suspension was seeded directly on the flat side of the $\mathrm{ZnS}$ hemisphere. The $\mathrm{ZnS}$ hemisphere carrying the cell suspension was incubated in the $\mathrm{CO}_{2}$ incubator for 12-24 h to allow the cells to attach to the $\mathrm{ZnS}$ surface. Once the cells are attached (observed through an inverted optical microscope), the DMEM medium was removed and $\mathrm{CO}_{2}$-independent L15 medium, supplemented with $10 \%$ FBS, 2 mM L-glutamine and $100 \mathrm{unit} / \mathrm{mL}$ of penicillin streptomycin, was added to the attached cell. The $\mathrm{ZnS}$ hemisphere with the attached cells was carefully loaded into a prototype transmission device where the cells are then sandwiched between the two $\mathrm{ZnS}$ hemispheres with a $12-\mu \mathrm{m}$ spacer. The prototype can hold $\sim 200 \mu \mathrm{L}$ of medium to maintain the viability of cells during measurement. Once the hemispheres were aligned in the microscope, a background was measured in an area with just medium but no cell attached. (Note that the medium contains mostly water with $0.3 \mathrm{wt} \%$ amino acids, $0.4 \mathrm{wt} \%$ protein, $0.02 \mathrm{wt} \%$ phosphate and $0.1 \mathrm{wt} \%$ carbohydrates, i.e. the compounds that may interfere with the spectrum are at a much lower concentration than in the living cell). A typical spectrum measured from the background region is shown in Electronic Supplementary Material (ESM) Fig. S1, which demonstrate the lack of interference from any organic compounds. FTIR images of the cell between the two $\mathrm{ZnS}$ hemispheres were then captured by mapping: i.e. sample scanning via $23 \mu \mathrm{m} \times 23 \mu \mathrm{m}$ aperture size in air (i.e. $10 \mu \mathrm{m} \times 10 \mu \mathrm{m}$ through the $\mathrm{ZnS}$ hemisphere) with a step size of $7 \mu \mathrm{m}$ (i.e. $3.1 \mu \mathrm{m}$ through the hemisphere) and a $6 \mu \mathrm{m} \times 6 \mu \mathrm{m}$ aperture size in air (i.e. $2.7 \mu \mathrm{m} \times 2.7 \mu \mathrm{m}$ through the hemisphere) with a step size of $2 \mu \mathrm{m}$ (i.e. $0.89 \mu \mathrm{m}$ through the hemisphere). Measurements were obtained by averaging 50 scans at $4 \mathrm{~cm}^{-1}$ spectral resolution giving a scanning time of $10 \mathrm{~s}$ per spectrum. Cell viability in the prototype transmission device for more than $12 \mathrm{~h}$ was confirmed using trypan blue assay (ESM Fig. S2).

\section{Results and discussion}

\section{Resolution target imaging}

The resolution test was carried out in reflection mode as the features on the USAF target were printed on a thick $(\sim 2 \mathrm{~mm})$ chromium plated glass slide which prevents the use of a matching $\mathrm{ZnS}$ hemisphere on the condenser side underneath the sample - required in transmission mode to obtain a good throughput of light (Fig. 1a). In reflection mode, the angle of incident at the $\mathrm{ZnS} / \mathrm{sample}$ interface from the $0.5 \mathrm{NA}$ objective is smaller than the critical angle; therefore, the measurement is made in transflection mode, not attenuated total internal reflection mode. The throughput of light was found to be high enough for the use of small aperture, which is critical to obtain high spatial resolution images. However, in reflection mode, the same objective is used for illumination and collection of light and the microscope is designed to achieved that by illuminating half of the objective to focus light onto the same while the other half to collect the light as shown in Fig. 1a. With this design, we have previously shown that the lateral spatial resolution along vertical axis will be at least twice lower [22]. Nevertheless, the experiment enabled the estimation of the lateral spatial resolution through the horizontal axis where the objective was fully illuminated.

The Rayleigh criterion, which was originally developed to define the resolving power of an optical system, was used for comparison purpose. When imaging two adjacent points with incoherent illumination and a circular aperture, the criterion for "just resolved" is when the maximum of the airy disc of one of the point overlaps with the first minimum of the airy disc of the other point. In this situation, the intensity at the middle between the two points will be $\sim 0.736$ of the maximum which produce a peak to trough intensity variation of $26.4 \%$. Although the situation with the imaging of the USAF target is not the same (the target was designed to be used as a qualitative measurement of spatial resolution), the criterion was found to be a useful guide for resolution comparison purpose between various imaging systems. FTIR images of the 1951 USAF resolution target measured at two spectral regions are shown in Fig. 2. Two spectral regions were examined. The $2900-2800 \mathrm{~cm}^{-1}$ and $1680-1560 \mathrm{~cm}^{-1}$ regions are respectively relevant to the lipids and proteins or fatty acids bands, which are important in organic matter analysis. The group 7 element 6 vertical line features with a line thickness of $2.19 \mu \mathrm{m}$ are clearly shown in all images and, as expected, the vertical line features are better resolved than the horizontal line features in all cases. The extracted profiles have shown that the vertical lines are all clearly shown, i.e. resolved. When using the $6 \mu \mathrm{m}$ aperture with a $2-\mu \mathrm{m}$ step size, the effective aperture size is reduced by the factor of the refractive index of the hemisphere ( 2.25 for $\mathrm{ZnS})$ to 2.7 and $0.89 \mu \mathrm{m}$, respectively. With this setting, the $2.19 \mu \mathrm{m}$ features were just resolved in 
Fig. 1 Schematics showing (a) the $\mathrm{ZnS}$ hemisphere on the USAF target where measurements were made in transflection mode and (b) the prototype transmission cell where live cells were sandwiched between two $\mathrm{ZnS}$ hemisphere with a $12-\mu \mathrm{m}$ thick spacer and the measurements were made in transmission mode

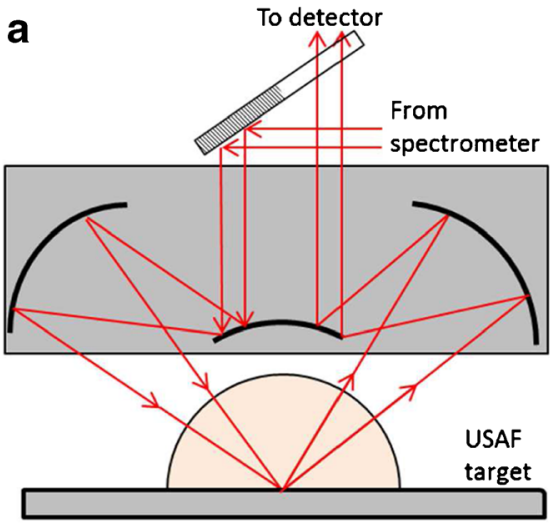

b

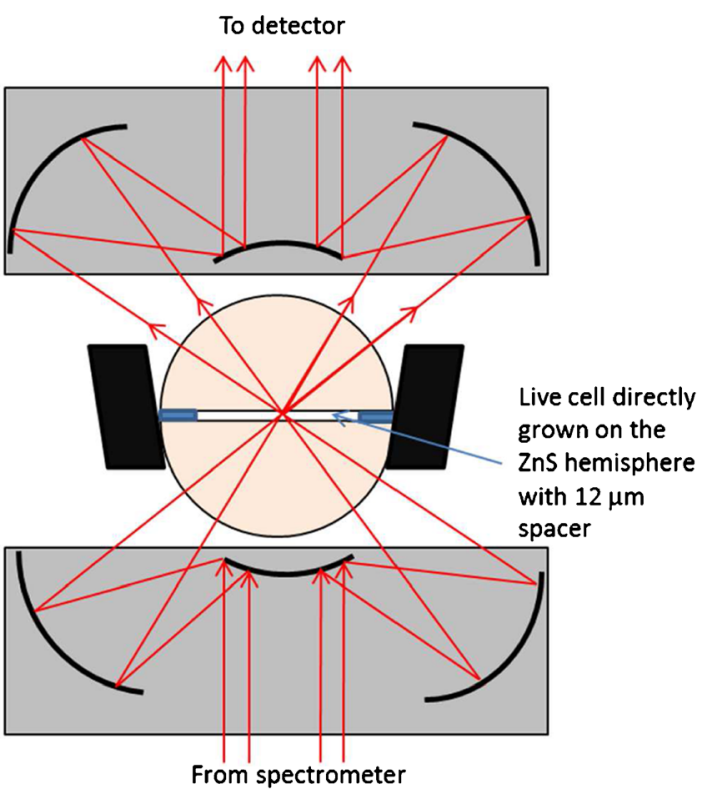

at the wavelength range of $1680-1560 \mathrm{~cm}^{-1}(\lambda \sim 6 \mu \mathrm{m})$ giving a spatial resolution of $\lambda / 2.7$. There is a further improvement in the sharpness in the profile with contrast of $\sim 40 \%$ with the same wavelength range when the aperture and step size are halved (Fig. 2a). However, the time taken for obtaining the image of the same area with the smaller aperture setting was quadrupled while the throughput of light was reduced by more than fourfold which makes it less practical for live cell studies but could be useful for other applications where the sample is stationary. The profiles measured using the $2900-2800 \mathrm{~cm}^{-1}$ range without the hemisphere with comparative effective aperture and step size are also added to Fig. 2a (aperture size of $1 \mu \mathrm{m}$, step size of $0.4 \mu \mathrm{m}$ ) and 2B (aperture size of $3 \mu \mathrm{m}$, step size of $1 \mu \mathrm{m}$ ) for comparison. In both cases, the lines were not

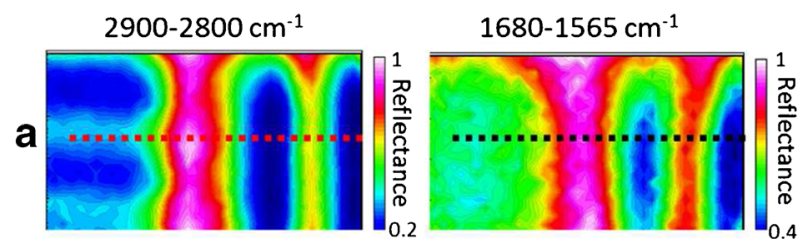

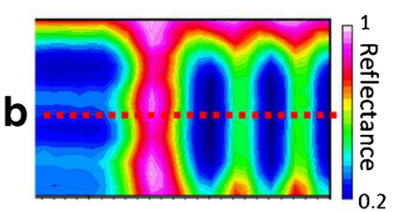

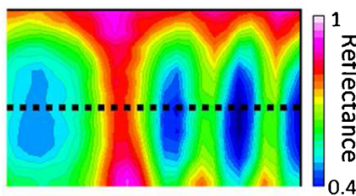

$2.19 \mu \mathrm{m}$

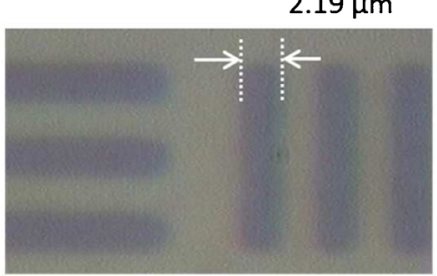

Fig. 2 FTIR, visible images and extracted transmittance profiles of the 1951 USAF resolution target measured through the $\mathrm{ZnS}$ hemisphere with (a) effective aperture size of $1.3 \mu \mathrm{m} \times 1.3 \mu \mathrm{m}$ with an effective step size of $0.44 \mu \mathrm{m}$ and (b) effective aperture size of $2.7 \mu \mathrm{m} \times 2.7 \mu \mathrm{m}$ with a set
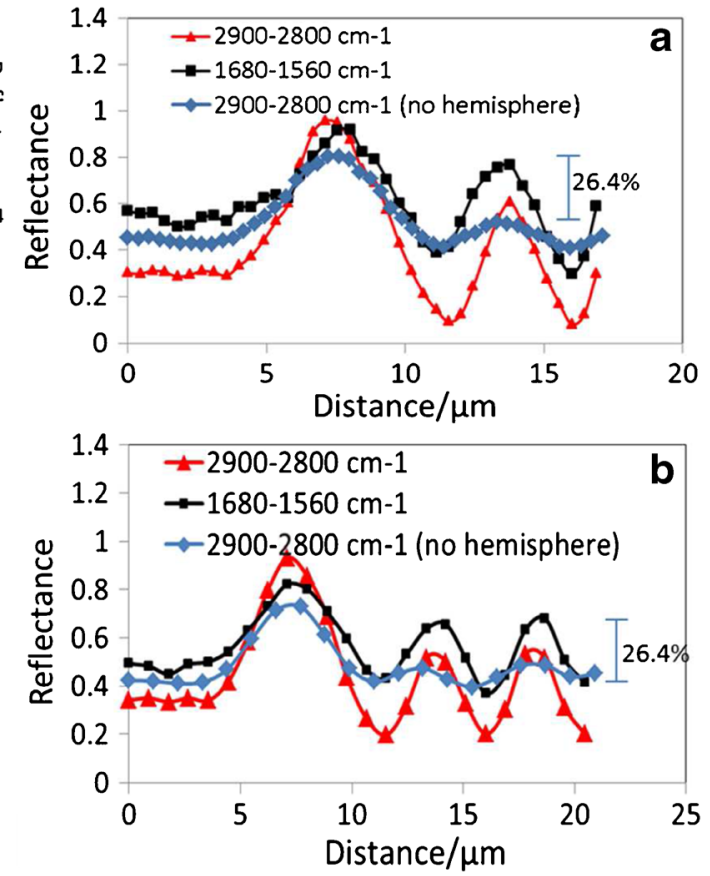

step size of $0.89 \mu \mathrm{m}$ for the black and red profiles. A blue profile is also added to the plots, which represents the measurement made without the hemisphere with (a) $1 \mu \mathrm{m} \times 1 \mu \mathrm{m}$ with an effective step size of $0.4 \mu \mathrm{m}$ and (b) $3 \mu \mathrm{m} \times 3 \mu \mathrm{m}$ with an effective step size of $1 \mu \mathrm{m}$ 
resolved without the hemisphere with contrast well below the $26.4 \%$ criterion.

Importantly, the results have demonstrated a significant improvement over previous non-ATR-based high resolution FTIR imaging studies that also published the contrast profiles of the USAF target including using multi-beam synchrotron imaging [30], $\mathrm{CaF}_{2}$ hemispheres [27] or the high magnification approach in transmission mode $[31,32]$. A similar improvement in spatial resolution was previous observed in ATR mode [33] and more recently when a Si immersion lens was used in back scattering mode (non-USAF target measurement) [34]. However, the latter work was not demonstrated with live cells but with polystyrene beads. While ATR mode has the potential to achieve higher spatial resolution, especially with a Ge lens [31], it is important to note that ATR mode measures the surface layer of the attached cell and the layer is thin with high refractive index elements (e.g. Ge with an angle of incidence of $30^{\circ}$ for NA of 0.5 or $37^{\circ}$ for NA of 0.6 produces a depth of penetration of $\sim 1.1$ and $0.8 \mu \mathrm{m}$, respectively, in the cell layer even at the longer wavelength of $1000 \mathrm{~cm}^{-1}$ ). This is in contrast to the full thickness of the sample (e.g. living cell) is measured in transmission mode. Also, the objective is half illuminated in ATR mode in a similar way as the transflection mode measurement demonstrated in Fig. 2. This is in contrast to the fully illuminated objective for the measurements made in transmission mode, as in the case of live cell measurement presented later and illustrated in Fig. 1. The high lateral spatial resolution is therefore maintained, unlike in ATR or transflection mode, along both vertical and horizontal axes of the image.

The improvement in the spatial resolution is due to the increase in NA by introducing the $\mathrm{ZnS}$ hemisphere in the path of the IR beam just above the sample. Interestingly, the NA of the objective is 0.5 , which is increased to 1.125 through the $\mathrm{ZnS}$ hemisphere, and the expected spatial resolution is calculated to be $3.3 \mu \mathrm{m}$ based on the Rayleigh criterion. However, the results have clearly demonstrated that the spatial resolution exceeded the estimation using the Rayleigh criterion by at least $30 \%$, which is in agreement with previous works by others using reverse Cassegrain objective with an FPA detector [30]. While that previous work was based on focal plane array detector, this work has also demonstrated a similar better-than-Rayleigh criterion spatial resolution can be observed by the mapping approach.

\section{Live cell imaging}

Figure 2 has shown that the $1.3 \mu \mathrm{m}$ effective aperture can produce a slightly better spatial resolution than the $2.7 \mu \mathrm{m}$ effective aperture. However, the time for mapping a large cell will be fourfold slower and therefore the $2.7 \mu \mathrm{m}$ effective aperture was used in all live cell measurements. The speed of the imaging measurement can be increased by using a focal

\section{a Visible image}
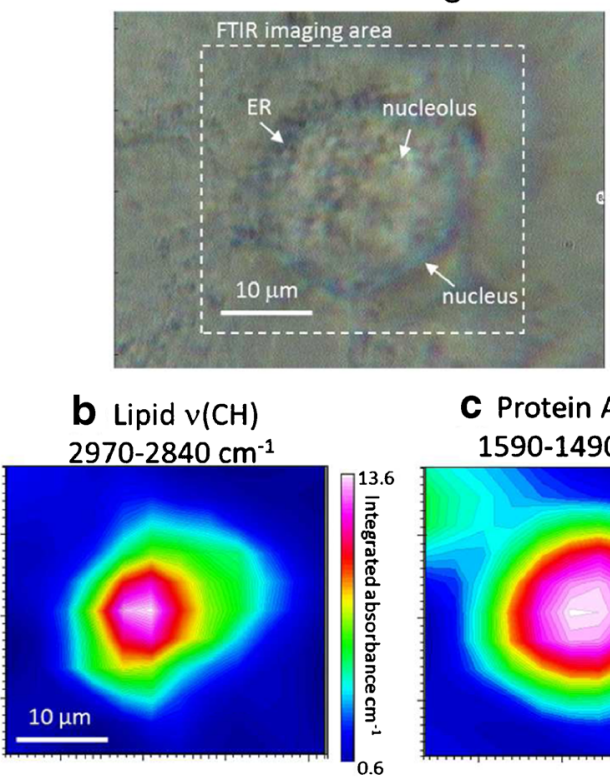

d Phospholipid $v(\mathrm{C}=\mathrm{O})$ $1768-1708 \mathrm{~cm}^{-1}$

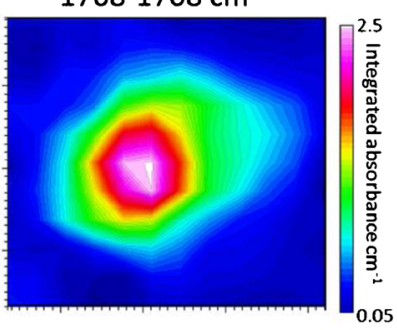

C Protein Amide II $1590-1490 \mathrm{~cm}^{-1}$

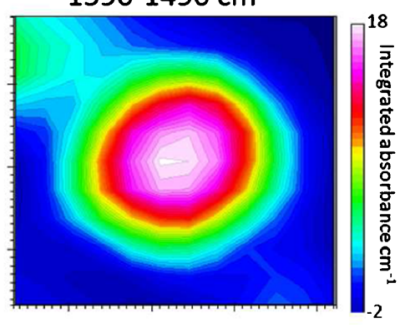

e Nucleic acids $v_{\text {sym }}\left(\mathrm{PO}_{2}\right)$ $1099-1082 \mathrm{~cm}^{-1}$
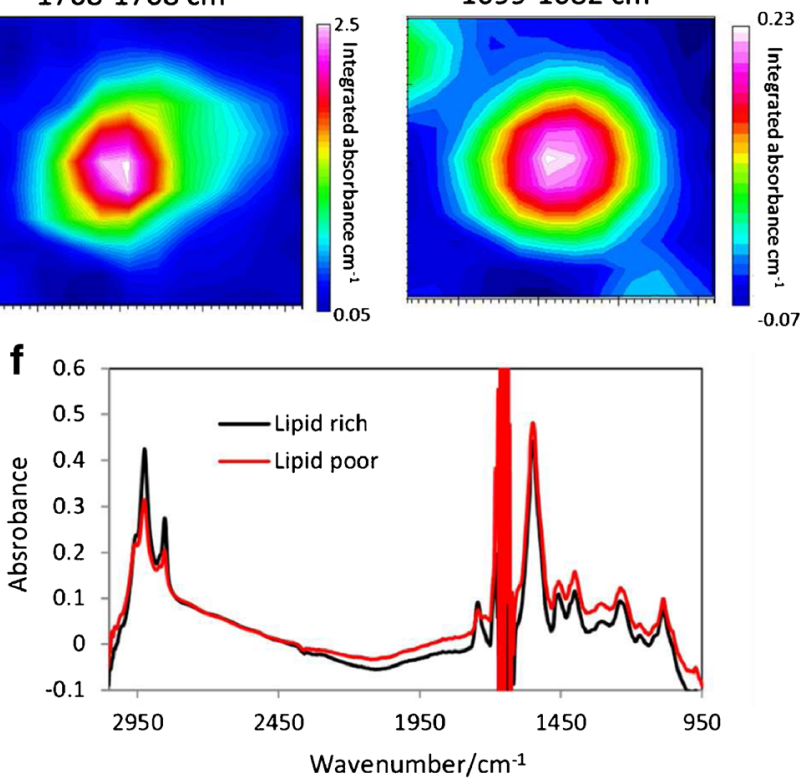

Fig. 3 Visible imaging (a) and FTIR images (b-e) of the living A549 cell in the region surrounding the nucleus in the $\mathrm{ZnS}$ hemispheres transmission device using an effective aperture size of $10 \mu \mathrm{m}$. Integration range $2970-2840 \mathrm{~cm}^{-1}, 1768-1708 \mathrm{~cm}^{-1}, 1590-1490 \mathrm{~cm}^{-1}$ and $1099-1082 \mathrm{~cm}^{-1}$ respectively represent the distribution of overall lipid (b), fat/phospholipids (d), the overall protein (amide II) (c) and nucleic acids (e). (f) shows the extracted spectra from the lipid rich (black line) and lipid poor (red line) areas spectra from positions 1 and 2 shown in $\mathbf{b}$

plane array (FPA) detector. Detailed comparisons between FPA and synchrotron system can be found elsewhere [35]. However, combining synchrotron source with an FPA has shown to produce benefit only at high magnification objectives or over small field of view areas [13] because of the diffraction limited microbeam, except when the unique 
multi-beam approach is used [30]. Furthermore, the benefit of the tightly focused source with the aperture on spatial resolution will be lost. Subsequently, the use of synchrotron source IR is advantageous at high magnification by exploiting image oversampling $[13,30]$. In this study, a comparison is made with the live cell imaged using the current standard synchrotron mapping protocol in transmission (Fig. 1b), which uses a $10 \mu \mathrm{m}$ effective aperture with $3 \mu \mathrm{m}$ step size and the results are shown in Fig. 3.

The results have shown that the living cell can be easily located by plotting the amide II absorbance (1590-1490 $\mathrm{cm}^{-1}$ ) across the mapped region. In this experiment, the imaging area is focused around the nucleus region of the cell where the thickness of the cell is greatest and many large intracellular organelles are located. The image shows the amide II, a key protein band, was used here rather than amide I because the absorbance of water with this transmission cell masked the amide I spectral region. During this experiment, only a slight pressure was applied between the two hemispheres to avoid physical damage to the living cells. There are rooms to refine the experimental procedures to incrementally increase the pressure to reduce the path length through the medium above cell for a better SNR. This will be refined in the future development of the prototype transmission device. The use of a thinner spacer will also reduce the contribution from the medium above the attached cell further improve the SNR of the measurement. Previous works have shown that cell remains viable for several hours when sandwiched between windows with a gap of a few $\mu \mathrm{m}[20,36]$ and $>60 \mathrm{~h}$ when subjected in a flow device [15]. Nevertheless, the current procedure enables the demonstration of the principle of subcellular imaging of living cells with the improved spatial resolution.

It is interesting to note that the distribution of the overall lipid represented by the $\mathrm{CH}_{2}$ and $\mathrm{CH}_{3}$ stretching mode vibration in the $2970-2840 \mathrm{~cm}^{-1}$ region has shown a smaller, more localised distribution than then the amide II-based protein map suggesting a lipid-rich organelle is present near the middle of the cell. The representative spectra (ratioed to the background spectrum measured from a near-by area that is not occupied by cells) extracted from the lipid-rich and lipid-poor region of the cell are shown in Fig. 3. While the amide II band shows a similar absorbance, the lipid bands from the lipid-rich region show a stronger absorbance than from the lipid-poor region, which demonstrates the images shown reflect the differences in the spectra. Compared to the earlier study where $\mathrm{CaF}_{2}$ hemispheres were used for live cell imaging, which has a spectral range cut-off at around $1100 \mathrm{~cm}^{-1}$, Fig. 3 shows that the spectral range can reach down to $950 \mathrm{~cm}^{-1}$ when using the $\mathrm{ZnS}$ hemispheres, which is critical for the study of DNAs $\left(1087 \mathrm{~cm}^{-1}\right.$ and $\left.\sim 970 \mathrm{~cm}^{-1}\right)$ and carbohydrates such as glycogen $\left(\sim 1150-1000 \mathrm{~cm}^{-1}\right)$.

FTIR images obtained by using the $10 \mu \mathrm{m}$ effective aperture, however, cannot distinguish the distribution of the
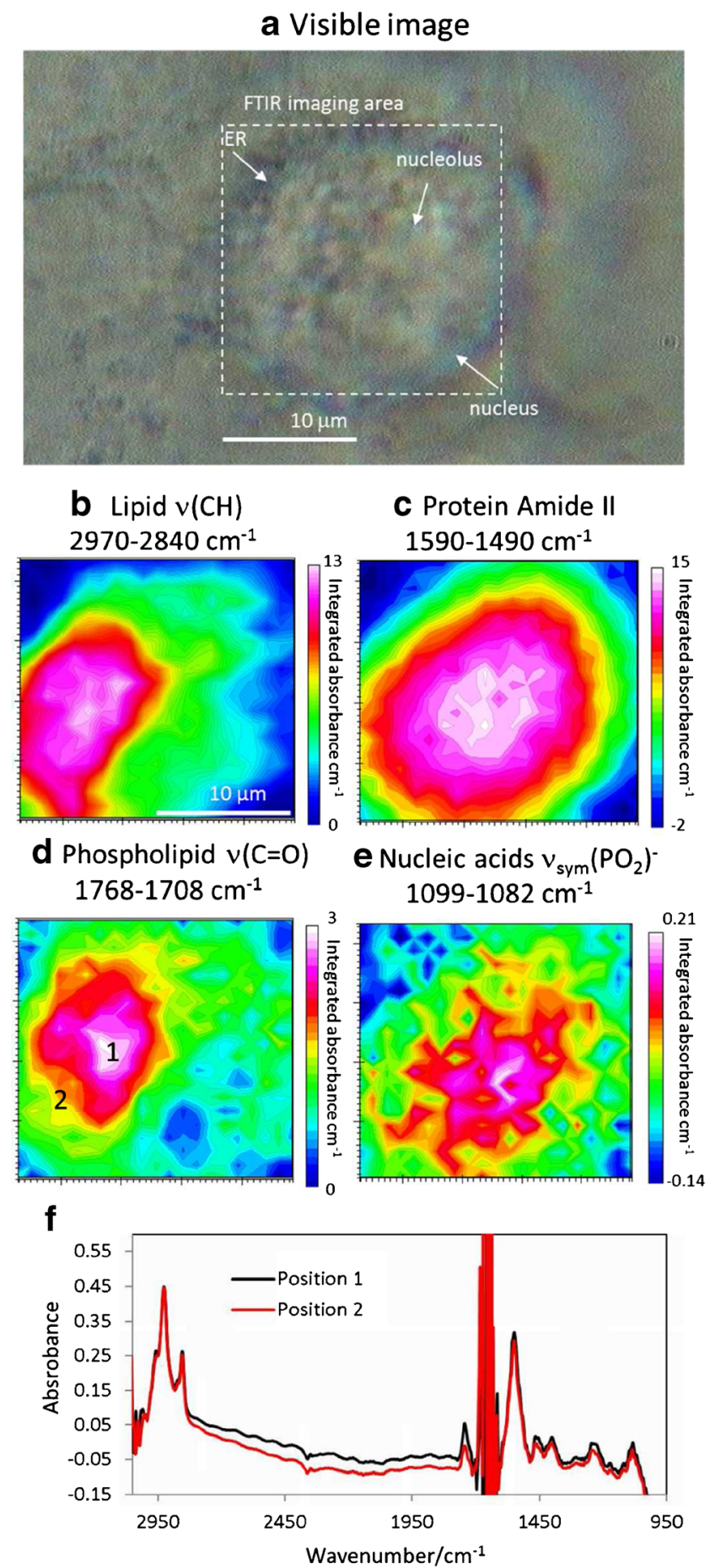

Fig. 4 Visible imaging (a) and FTIR images (b-e) of the living A549 cell in the region surrounding the nucleus in the $\mathrm{ZnS}$ hemispheres transmission device using an effective aperture size of $2.7 \mu \mathrm{m}$. Integration range $2970-2840 \mathrm{~cm}^{-1}, 1768-1708 \mathrm{~cm}^{-1}, 1590-1490 \mathrm{~cm}^{-1}$ and $1099-1082 \mathrm{~cm}^{-1}$ respectively represent the distribution of overall lipid (b), fat/phospholipids (d), the overall protein (amide II) (c) and nucleic acids (e). (f) shows the extracted spectra from positions 1 and 2 shown in $\mathbf{d}$

carbonyl containing phospholipids, which is mapped by using the $1768-1708 \mathrm{~cm}^{-1}$ band (peak at $1745 \mathrm{~cm}^{-1}$ ), from the general lipids $\left(2970-2840 \mathrm{~cm}^{-1}\right)$. This is expected because 
the size aperture used is about the same as the size of the lipidrich organelle. The same cell was immediately mapped again using the $2.7 \mu \mathrm{m}$ effective aperture and $0.89 \mu \mathrm{m}$ step size, and the results are shown in Fig. 4. FTIR images generated though the amide II protein band highlighted the centre of the cell where the strongest absorbance occur at the middle. Note that the length scale of the images in Fig. 4 is smaller than in Fig. 3 because of the higher pixel density used. Comparing to the images shown in Fig. 3, the images in Fig. 4 revealed a greater detail on the lipid distribution within the cell. The image generated using the lipid $v(\mathrm{CH})$ bands in $2970-2840 \mathrm{~cm}^{-1}$ region has shown a clear image of the lipid-containing organelles which are mainly located to the left of the centre of the cell. Previous imaging on fixed dried fibroblast cell has also shown that detailed distribution of lipids can only be obtained when high definition approach is used, despite fibroblast cells are generally larger than the A549 cell used in this study [37]. The distribution of the carbonyl containing phospholipids (the image generated based on the band in between 1768 and
$1708 \mathrm{~cm}^{-1}$ ), however, has a slightly different distribution to the overall lipids. This is also observed from the representative spectra extracted from positions 1 and 2 in Fig. 4 where both spectra show the same absorbance in the $2970-2840 \mathrm{~cm}^{-1}$ region but different absorbance in the carbonyl 1768$1708 \mathrm{~cm}^{-1}$ region. This is also shown by the extracted spectra from locations 1 and 2 on the carbonyl map. We have measured three separately cultured living cells and a similar observation was made (see ESM Fig. S3). This suggests that the lipid within the organelle is not homogeneous or there were two lipid-rich organelles next to each other. One of the largest lipid-rich intracellular organelles that is close to the nucleus is the endoplasmic reticulum (ER). It consists of membrane lipid formed tubules and cisternae which can produce strong $v(\mathrm{CH})$ and $v(\mathrm{C}=\mathrm{O})$ bands. Some of the major functions of the ER include protein sorting and transportation by the production of vesicles (rough ER) as well as lipid synthesis (smooth ER). The FTIR images of the lipid in Fig. 4 therefore match well to the expected chemical composition, size and location of ER.
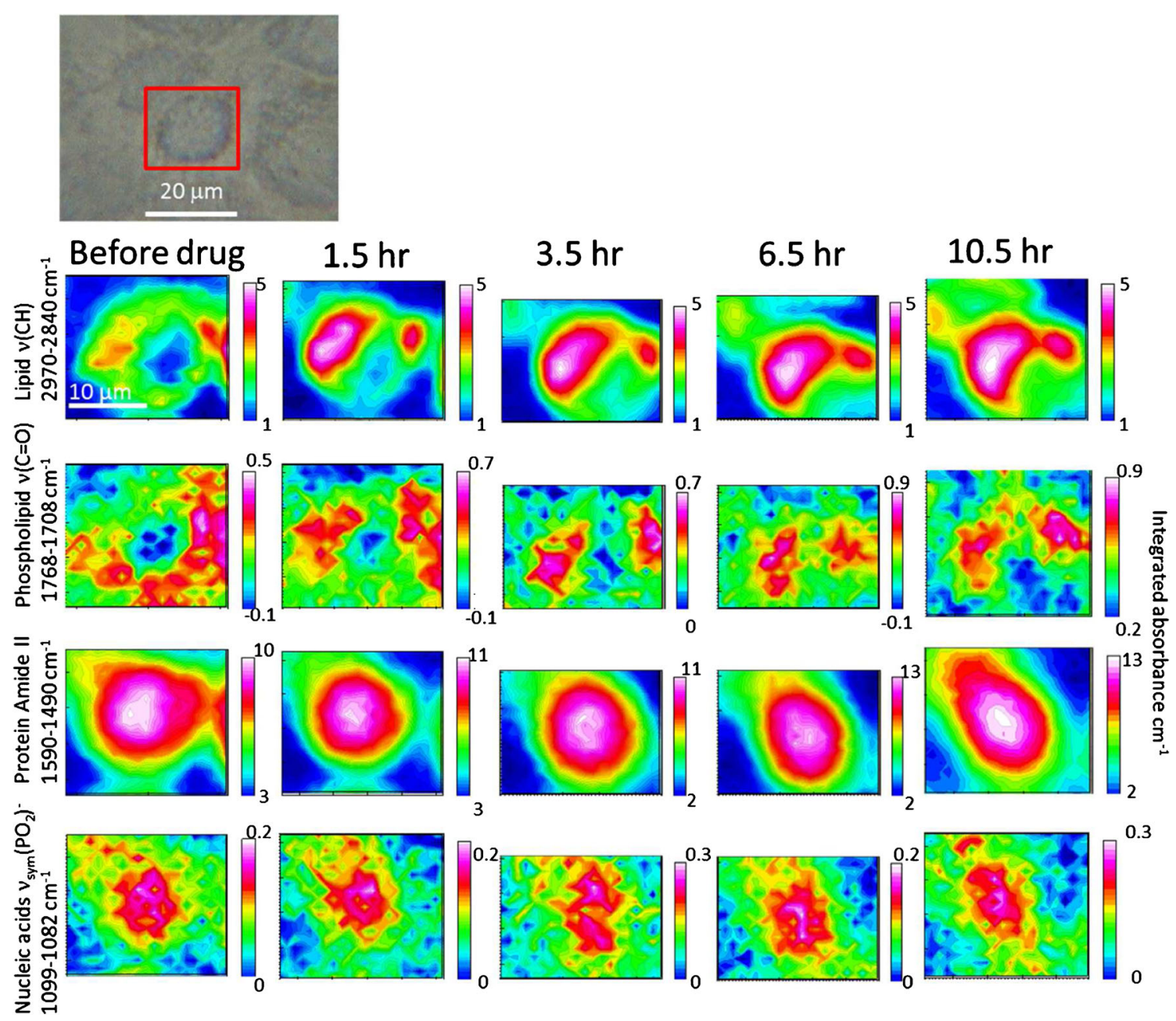

Fig. 5 FTIR images of an A549 cell in the region surrounding the nucleus before and after exposure to $0.5 \mu \mathrm{M}$ doxorubicin. The visible image of the measured A549 cell is shown at the top with the red square showing the approximate location where the FTIR images were measured. The colour scales used are shown on the right of each individual image 

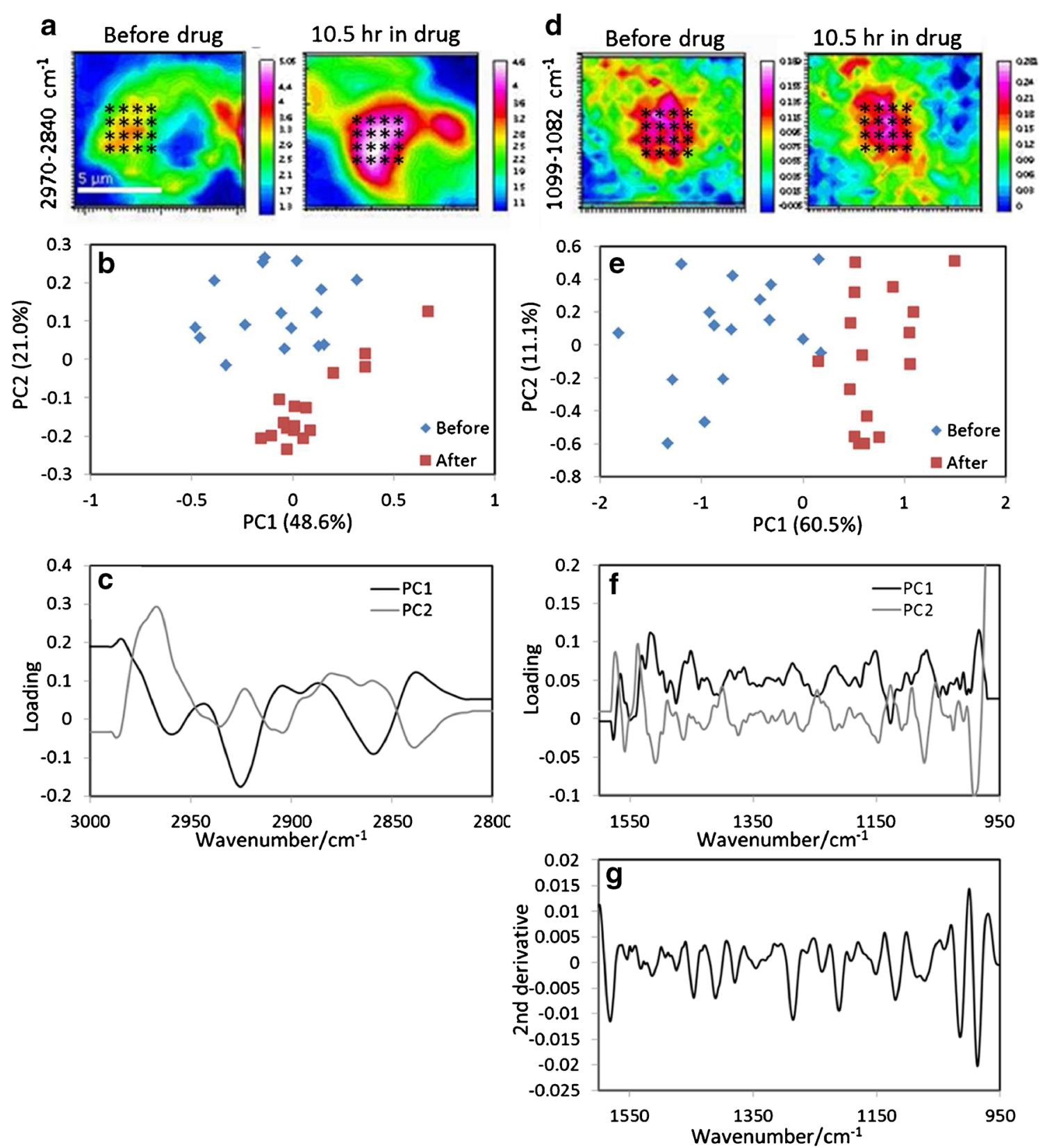

Fig. 6 PCA analysis of the cell before and after exposing in drug for $10.5 \mathrm{~h}$. The "**" marks on images in (a) and (d) show the locations of the extracted spectra. Normalised (max-min) second derivative spectra were used to calculate the PCs. (b) Score plots of PC1 against PC2 in the $3000-2800 \mathrm{~cm}^{-1}$ region from the spectra extracted from locations

The variation in the $v(\mathrm{C}=\mathrm{O})$ bands within the lipid region might be speculated as the differences in composition of the lipid between the rough and smooth ER. Previous live cell imaging using micro ATR approach has shown that ER contains a higher amount of glycogen than the other parts of the cell, which is not observed in this case [3]. However, the previous work imaged SKOV cells which are different to A549 cells, and the sampling volume in ATR mode is different to the transmission mode used in this study. The image created from the $1087 \mathrm{~cm}^{-1}\left(1099-1082 \mathrm{~cm}^{-1}\right)$ band, which mainly

indicated in (a). Plot (c) is the loadings for PC1 and PC2 correspond to (b). (e) Score plots of PC1 against PC2 in the $1600-950 \mathrm{~cm}^{-1}$ region from the spectra extracted from locations indicated in (d). Plot (f) is the loadings for $\mathrm{PC} 1$ and $\mathrm{PC} 2$ correspond to (d). (g) A second derivative spectrum $\left(1600-950 \mathrm{~cm}^{-1}\right)$ of doxorubicin in solution form

contributed from the nucleic acid of the cell, shows a localised concentration at the middle of the image. This suggests this map represents the location of the DNA cluster in the nucleus.

\section{Drug in live cells}

To demonstrate the potential of this approach to observe realtime subcellular changes and observe the differences between living and drug-treated cells, live cells were exposed in a wellknown anti-cancer agent (doxorubicin) at $\mathrm{IC}_{50}$ concentration 
( $\sim 0.5 \mu \mathrm{M}$ for $24 \mathrm{~h}$ exposure) $[38,39]$ with FTIR images of the cell captured as a function of time. The results are shown in Fig. 5. The images generated based on the $v(\mathrm{CH})$ bands show that the distribution of the lipid at the beginning was more defined in the surrounding of the nucleus of the cell, which spread towards the middle of the nucleus and to the top left part outside of nucleus of the cell after the addition of drug. The phospholipid map shows distribution similar to, but not the same as, the lipid map based on the $v(\mathrm{CH})$ bands. As mentioned previously, these regions with high $v(\mathrm{CH})$ and $v(\mathrm{C}=\mathrm{O})$ absorbance bands, correspond to phospholipid synthesis regions of the ER. The observed spread of the lipid region can be explained by the production of vesicles which spread across the cell as a response to the drug in the early stage of apoptosis [40]. While it is not possible to determine if the cell was already dead at $10.5 \mathrm{~h}$, trypan blue assay performed on the cells at the end of the experiment, which involved opening the device and injection of the trypan blue solution to the cell, has shown that most cells absorbed the blue dye, confirming cell death, in contrast to the control in ESM Fig. S2 which has shown that most cells were not stained. Similar observations were made on the repeated study based on a separately cultured A549 cell (ESM Fig. S3). The protein amide II maps and the nucleic acid band highlighted a small change in the shape of the cell, which could be a result of the natural movement of the cell. Although the trypan blue assay suggested most of the cells were dead, the causes of the relatively rapid cell death remain less clear. It was not expected all cells will die after $\sim 10 \mathrm{~h}$ of doxorubicin treatment based on the concentration of the drug used. The relatively rapid cell death could have been accelerated by other factors such as the confined volume of the device or the disturbance to the cell during the opening of the device for the injection of the trypan blue solution. Nevertheless, this uncertainty does not neglect the results shown in this work, which demonstrated the resolution capability of the presented technique.

Comparing the spectral regions where key absorbance of the cells are $\left(2800-3000 \mathrm{~cm}^{-1}\right.$ and $\left.950-1000 \mathrm{~cm}^{-1}\right)$, spectra extracted from the lipid and the nucleic acids areas (shown in Fig. 6a, d) using principal component analysis (PCA) has shown that spectra were distinguishable before and $10.5 \mathrm{~h}$ after the treatment of drug. Figure $6 \mathrm{~b}$ shows that PC2 (Fig. 6c) separated the spectra extracted before and after drug treatment in the lipid-rich region. However, the bands shown in the PCs do not coincide with the lipid peak which can be interpreted as a shift in the bands between the before and after drug treatment spectra. Figure 6e shows that mainly PC1 produced the separation between the before and after drug treatment spectra in the fingerprint region. The PC1 (Fig. 6f) shows main difference can be found in the amide II and the $1000-1125 \mathrm{~cm}^{-1}$ regions. These changes were not observed from the raw data but were distinguished when PCA is applied. Previous studies by Byrne's group $[38,39]$ on the same cell line treated in doxorubicin using Raman spectroscopy have shown that the drug accumulated in the nucleus of the treated cells. However, comparing $\mathrm{PC} 1$ to the spectrum of doxorubicin (2nd derivative) in Fig. 6g, there is no clear resemblance of doxorubicin spectral feature in $\mathrm{PC} 1$ suggesting the ability of PCA to separate the spectra before and after the addition of the drug is from the cellular responses to the drug rather than the absorbance of the drug. The lack of doxorubicin absorbance could be due to the low concentration of drug in the living cell. The changes in the $1000-1125 \mathrm{~cm}^{-1}$ can be a result of the action of drug, which is a DNA intercalator. It is important to note that while the results from the drug study are interesting, confirmation of the mode of action of drug, which is beyond the scope of the current work, will require more repeated experiments.

\section{Conclusions}

Synchrotron FTIR combined with the hemispherical lens approach is a powerful method for live cell FTIR imaging with subcellular spatial resolution. The high brightness and the ability to focus the IR light to a diffraction limited spot with synchrotron has enabled the use of small apertures without significant loss in energy throughput. When combined with the use of $\mathrm{ZnS}$ hemispheres, which increase the NA of the objective and further reduce the diffraction limited spot-size by $2.25 \times$, features as small as $2.19 \mu \mathrm{m}$ were laterally resolved at $\sim 6 \mu \mathrm{m}$ wavelength, i.e. a lateral spatial resolution of at least $\lambda / 2.7$. Subcellular features, thereby, can be imaged with the improved spatial resolution. Different images of lipids, based on the alkane chain $v(\mathrm{CH})$ band $\left(2970-2840 \mathrm{~cm}^{-1}\right)$, carbonyl band (1768-1708 $\left.\mathrm{cm}^{-1}\right)$ and DNA band (1099$1082 \mathrm{~cm}^{-1}$ ), within a living A549 cell surrounding the nucleus are were obtained. The ability to monitor the spatial distribution of various components inside the single cell in this experiment clearly demonstrated the advantages of high spatial resolution image of live cells. A preliminary test of drug treated in an anti-cancer agent doxorubicin is also shown, demonstrating the potential to study the dynamic changes in cells as a result of drug treatment. The study of changes in the same cells upon drug treatment is not possible with fixed cell measurements.

Acknowledgements We thank Diamond Light Source for access to beamline SM14912 that contributed to the results presented here. We thank the Prince Sattam Bin Abdulaziz University for Ali Altharawi's $\mathrm{PhD}$ scholarship. We also thank the University of Lisbon for sponsoring the travel of Dr. Fale.

\section{Compliance with ethical standards}

Conflict of interest There is no potential conflict of interest from this work. 
Open Access This article is distributed under the terms of the Creative Commons Attribution 4.0 International License (http:// creativecommons.org/licenses/by/4.0/), which permits unrestricted use, distribution, and reproduction in any medium, provided you give appropriate credit to the original author(s) and the source, provide a link to the Creative Commons license, and indicate if changes were made.

\section{References}

1. Vaccari L, Birarda G, Businaro L, Pacor S, Grenci G. Infrared microspectroscopy of live cells in microfluidic devices (MDIRMS): toward a powerful label-free cell-based assay. Anal Chem. 2012;84(11):4768-75. https://doi.org/10.1021/ac300313x.

2. Schmidt M, Wolfram T, Rumpler M, Tripp CP, Grunze M. Live cell adhesion assay with attenuated total reflection infrared spectroscopy. Biointerphases. 2007;2(1):1-5. https://doi.org/10.1116/1. 2710336.

3. Kuimova MK, Chan KLA, Kazarian SG. Chemical imaging of live cancer cells in the natural aqueous environment. Appl Spectrosc. 2009;63(2):164-71.

4. Alam MK, Timlin JA, Martin LE, Williams D, Lyons CR, Garrison $\mathrm{K}$, et al. Spectroscopic evaluation of living murine macrophage cells before and after activation using attenuated total reflectance infrared spectroscopy. Vib Spectrosc. 2004;34(1):3-11. https://doi. org/10.1016/j.vibspec.2003.07.002.

5. Marcsisin EJ, Uttero CM, Miljkovic M, Diem M. Infrared microspectroscopy of live cells in aqueous media. Analyst. 2010;135(12):3227-32. https://doi.org/10.1039/c0an00548g.

6. Chan KLA, Fale PLV. Label-free in situ quantification of drug in living cells at micromolar levels using infrared spectroscopy. Anal Chem. 2014;86(23):11673-9. https://doi.org/10.1021/ac503915c.

7. Fale PLV, Altharawi A, Chan KLA. In situ Fourier transform infrared analysis of live cells' response to doxorubicin. BBA-Mol Cell Res. 2015;1853(10 Part A):2640-8.

8. Chan KLA, Fale PLV. Label-free optical imaging of live cells. In: Meglinski I, editor. Biophotonics for medical applications. Woodhead Publishing; 2015. p. 215-41.

9. Vongsvivut J, Heraud P, Gupta A, Thyagarajan T, Puri M, McNaughton D, et al. Synchrotron-FTIR microspectroscopy enables the distinction of lipid accumulation in thraustochytrid strains through analysis of individual live cells. Protist. 2015;166(1):10621. https://doi.org/10.1016/j.protis.2014.12.002.

10. Munro KL, Bambery KR, Carter EA, Puskar L, Tobin MJ, Wood $\mathrm{BR}$, et al. Synchrotron radiation infrared microspectroscopy of arsenic-induced changes to intracellular biomolecules in live leukemia cells. Vib Spectrosc. 2010;53(1):39-44. https://doi.org/10. 1016/j.vibspec.2010.02.004.

11. Doherty J, Cinque G, Gardner P. Single-cell analysis using Fourier transform infrared microspectroscopy. Appl Spectrosc Rev. 2017;52(6):560-87. https://doi.org/10.1080/05704928.2016. 1250214 .

12. Chan KLA, Kazarian SG. Aberration-free FTIR spectroscopic imaging of live cells in microfluidic devices. Analyst. 2013;138: 4040-7. https://doi.org/10.1039/c3an00327b.

13. Quaroni L, Zlateva T, Sarafimov B, Kreuzer HW, Wehbe K, Hegg EL, et al. Synchrotron based infrared imaging and spectroscopy via focal plane array on live fibroblasts in D2O enriched medium. Biophys Chem. 2014;189:40-8. https://doi.org/10.1016/j.bpc. 2014.03.002.

14. Quaroni L, Zlateva T, Wehbe K, Cinque G. Infrared imaging of small molecules in living cells: from in vitro metabolic analysis to cytopathology. Faraday Discuss. 2016;187:259-71. https://doi.org/ $10.1039 / \mathrm{c} 5 \mathrm{fd} 00156 \mathrm{k}$.
15. Birarda G, Ravasio A, Suryana M, Maniam S, Holman HYN, Grenci G. IR-Live: fabrication of a low-cost plastic microfluidic device for infrared spectromicroscopy of living cells. Lab Chip. 2016;16(9):1644-51. https://doi.org/10.1039/c5lc01460c.

16. Birarda G, Grenci G, Businaro L, Marmiroli B, Pacor S, Piccirilli F, et al. Infrared microspectroscopy of biochemical response of living cells in microfabricated devices. Vib Spectrosc. 2010;53(1):6-11. https://doi.org/10.1016/j.vibspec.2010.01.016.

17. Birarda G, Grenci G, Businaro L, Marmiroli B, Pacor S, Vaccari L. Fabrication of a microfluidic platform for investigating dynamic biochemical processes in living samples by FTIR microspectroscopy. Microelectron Eng. 2010;87(5-8):806-9. https://doi.org/10.1016/j.mee.2009.11.081.

18. Tobin MJ, Puskar L, Barber RL, Harvey EC, Heraud P, Wood BR, et al. FTIR spectroscopy of single live cells in aqueous media by synchrotron IR microscopy using microfabricated sample holders. Vib Spectrosc. 2010;53(1):34-8. https://doi.org/10.1016/j.vibspec. 2010.02.005.

19. Quaroni L, Zlateva T. Infrared spectromicroscopy of biochemistry in functional single cells. Analyst. 2011;136(16):3219-32. https:// doi.org/10.1039/c1an15060j.

20. Gelfand P, Smith RJ, Stavitski E, Borchelt DR, Miller LM. Characterization of protein structural changes in living cells using time-lapsed FTIR imaging. Anal Chem. 2015;87(12):6025-31. https://doi.org/10.1021/acs.analchem.5b00371.

21. Mattson EC, Aboualizadeh E, Barabas ME, Stucky CL, Hirschmugl CJ. Opportunities for live cell FT-infrared imaging: macromolecule identification with $2 \mathrm{D}$ and $3 \mathrm{D}$ localization. Int $\mathrm{J}$ Mol Sci. 2013;14(11):22753-81. https://doi.org/10.3390/ ijms 141122753 .

22. Kazarian SG, Chan KLA. Micro- and macro-attenuated total reflection Fourier transform infrared spectroscopic imaging. Appl Spectrosc. 2010;64(5):135A-52A.

23. Fale PLV, Chan KLA. Preventing damage of germanium optical material in attenuated total reflection-Fourier transform infrared (ATR-FTIR) studies of living cells. Vib Spectrosc 2016; in press.

24. Lewis EN, Treado PJ, Reeder RC, Story GM, Dowrey AE, Marcott $\mathrm{C}$, et al. Fourier transform spectroscopic imaging using an infrared focal-plane array detector. Anal Chem. 1995;67(19):3377-81.

25. Carr GL. Resolution limits for infrared microspectroscopy explored with synchrotron radiation. Rev Sci Instrum. 2001;72(3):1613-9. https://doi.org/10.1063/1.1347965.

26. Wetzel DL. A new approach to the problem of dispersive windows in infrared microspectroscopy. Vib Spectrosc. 2002;29(1-2):291-7.

27. Chan KLA, Kazarian SG. Correcting the effect of refraction and dispersion of light in FT-IR spectroscopic imaging in transmission through thick infrared windows. Anal Chem. 2013;85(2):1029-36. https://doi.org/10.1021/ac302846d.

28. Wehbe K, Filik J, Frogley MD, Cinque G. The effect of optical substrates on micro-FTIR analysis of single mammalian cells. Anal Bioanal Chem. 2013;405(4):1311-24. https://doi.org/10. 1007/s00216-012-6521-6.

29. Yao S, Guidi MC, Delugin M, Della-Ventura G, Marcelli A, Petibois C. Methodology for FTIR imaging of individual cells. Acta Phys Pol A. 2016;129(2):250-4.

30. Nasse MJ, Walsh MJ, Mattson EC, Reininger R, Kajdacsy-Balla A, Macias V, et al. High-resolution Fourier-transform infrared chemical imaging with multiple synchrotron beams. Nat Methods. 2011;8(5):413-6. https://doi.org/10.1038/nmeth.1585.

31. Findlay CR, Wiens R, Rak M, Sedlmair J, Hirschmugl CJ, Morrison J, et al. Rapid biodiagnostic ex vivo imaging at $1 \mathrm{mu} \mathrm{m}$ pixel resolution with thermal source FTIR FPA. Analyst. 2015;140(7):2493-503. https://doi.org/10.1039/c4an01982b.

32. Kimber JA, Foreman L, Turner B, Rich P, Kazarian SG. FTIR spectroscopic imaging and mapping with correcting lenses for 
studies of biological cells and tissues. Faraday Discuss. 2016;187: 69-85. https://doi.org/10.1039/c5fd00158g.

33. Chan KLA, Kazarian SG. New opportunities in micro- and macroattenuated total reflection infrared spectroscopic imaging: spatial resolution and sampling versatility. Appl Spectrosc. 2003;57(4): 381-9.

34. Kumbham M, Daly S, O'Dwyer K, Mouras R, Liu N, Mani A, et al. Doubling the far-field resolution in mid-infrared microscopy. Opt Express. 2016;24(21):24377-89. https://doi.org/10.1364/oe.24. 024377.

35. Levenson E, Lerch P, Martin MC. Infrared imaging: synchrotrons vs. arrays, resolution vs. speed. Infrared Phys Technol. 2006;49(12):45-52. https://doi.org/10.1016/j.infrared.2006.01.026.

36. Mitri E, Kenig S, Coceano G, Bedolla DE, Tormen M, Grenci G, et al. Time-resolved FT-IR microspectroscopy of protein aggregation induced by heat-shock in live cells. Anal Chem. 2015;87(7):36707. https://doi.org/10.1021/ac5040659.
37. Hughes C, Henderson A, Kansiz M, Dorling KM, JimenezHernandez M, Brown MD, et al. Enhanced FTIR bench-top imaging of single biological cells. Analyst. 2015;140(7):2080-5. https:// doi.org/10.1039/c4an02053g.

38. Farhane Z, Bonnier F, Casey A, Byrne HJ. Raman micro spectroscopy for in vitro drug screening: subcellular localisation and interactions of doxorubicin. Analyst. 2015;140(12):4212-23. https:// doi.org/10.1039/c5an00256g.

39. Farhane Z, Bonnier F, Howe O, Casey A, Byrne HJ. Doxorubicin kinetics and effects on lung cancer cell lines using in vitro Raman micro-spectroscopy: binding signatures, drug resistance and DNA repair. J Biophotonics. 2018;11(1) https://doi.org/10.1002/jbio. 201700060.

40. Bottone MG, Santin G, Aredia F, Bernocchi G, Pellicciari C, Scovassi AI. Morphological features of organelles during apoptosis: an overview. Cell. 2013;2:294-305. 